\title{
Mobile Technology for Volunteers in the Distribution of Natural Disaster Humanitarian Logistics: Case study on East Java Province Indonesian Red Cross
}

\author{
Djoni Haryadi Setiabudi ${ }^{1+}$, I Gede A. Widyadana ${ }^{2}$ \\ ${ }^{1}$ Informatics Department, Petra Christian University, Indonesia \\ ${ }^{2}$ Industrial Engineering Department, Petra Christian University, Indonesia
}

\begin{abstract}
On the events of natural disasters such as volcano eruptions, floods, landslides, tsunamis etc, volunteers play important roles in disasters management. The volunteers have to deal with the problem of managing the logistics to be distributed to the victims of the natural disasters. The logistics distribution for the victims of the disasters is hampered with the process of distributing goods from the central IRC (Indonesian Red Cross) to the shelters at the sites of the natural disasters. Often, the amount of goods sent, does not match with the amount of goods received. Sometimes the goods sent, also do not meet the needs of the victims due to the problems in data recording. There have not been many studies on this issue related to this kind of problems faced by volunteers. Some conducted studies, among others, were related to the logistics distribution methods, the speed of distribution, locating the shortest distance to the sites of the disasters. This study is developing a mobile application to facilitate easier logistics management between the Indonesian Red Cross, as the disaster management agency, the shelters and the volunteers at the disaster sites. The main focus is to meet the appropriate logistic requirements in sufficient quantity for the victims of the natural disasaters. The result of this study is the development of a mobile application for volunteers able to accurately record all logistical needs and supplies at the disaster sites.
\end{abstract}

Keywords: logistics, volunteers, natural disaster, mobile technology, humanitarian

\section{Introduction}

Located in the equator with diverse land morphologies from plateaus up to high mountains, Indonesia, geographically, is included in the most vulnerable countries in natural disasters. Many natural disasters occur in Indonesia, in the form of volcano eruptions, earthquakes, landslides, flash floods etc. The government has formed a National Disaster Management Agency, called BNPB, in the national level and a Regional Disaster Management Agency, called BPBD, in the regional level. Besides BPBD, The Indonesian Red Cross, plays an important role in managing disasters. IRC has the responsibilities before, during and after disasters [1]. Every time a natural disaster occurs, the government sends volunteers to the disaster site, bringing with them some logistics aids for the disaster victims. For this purpose, the government set up a shelter, close to the disaster site. In channeling the disaster logistics, IRC is facing a problem of distribution. There is often no clear coordination between the central IRC and the shelter receiving the goods. The goods sent often do not match with the goods received by the volunteers at the shelter, in terms of the item types as well as the quantity of the goods requested. This miscommunication happens as those persons in charge are still using phones, either in the form of voice calls, sms or WhatsApp chats. Therefore, there is a need for using asoftware for communication between the central IRC and the volunteers on duty at the shelter at the disaster site [2]. The volunteers have to be able to submit a detailed list of goods required in terms of types and quantity to the central IRC. The central IRC has to prepare the logistics to meet the request and send them to the disaster site. This study is to fill the gap that has not been so much addressed on the studies of natural

\footnotetext{
+ Corresponding author. Tel.: +628974049299

E-mail address: djonihs@petra.ac.id
} 
disaster, in the form of a mobile application. This application is to facilitate the volunteers in managing the process of meeting the needs of the disaster victims in terms of accurate types and the quantity of the logistics goods.

\section{Literature Review}

Logistics plays an important role in managing disasters especially on the event of pre-disaster, the alertness and responses for disasters management. An effective, efficient and reliable logistics management plays an essential role in managing disasters [3]. The use of a centralized information and communication system will be able to increase the effectiveness of managing emergency cases caused by extreme weather and climate issues. This information system is based on the use of a mobile application linked to a web based centralized decision support system [4]. Logistics is an important element in every humanitarian relief effort or disaster aid. How the humanitarian relief logistics is managed, will determine the success or failure of the disaster management operation [5]. The study on the performance of relief logistics in Ghana, which was discussing the resource ability, effectiveness of the inventory management and the coordination in managing disasters, showed that there was a fast assesment in managing natural disaster. Unfortunately, the logistics delivery process is very slow [6]. Humanitarian relief logistics management covers the activities of planning, operating and monitoring in channeling the humanitarian reliefs efficiently from the original point to the consumption point for the purpose of reducing the sufferings of the disaster victims [7]. Serrato-Garcia, et.al [8] conducted a study on the use of mobile technology to present the development and implementation of multi purpose optimization model and mobile technology based information system to support the decision making in the humanitarian logistics operation. However, this model did not work with other humanitarian reliefs, such as for volunteers. Abushaikha and Schumann-Bölsche [9], conducted a study on the increasing interest on the role of logistic function in supporting the humanitarian relief operation. The object of their study was to evaluate the appropriateness of mobile phone technology in supporting humanitarian operation. However, this study did not specifically support the role of mobile phones for volunteers.

\section{Research Methodology}

\subsection{System analysis}

Currently, East Java Province is actively involved in channeling humanitarian relief logistics for natural disasters. When a natural disaster occurs, a team of volunteers will be sent directly to the disaster site. At the disaster site, there is a shelter for coordination with the volunteers and to store the logistics sent from Surabaya IRC. There have been many donors providing aids for the natural disaster victims through IRC, but they prefer sending goods compared to money, as there has not been an administration process for recording donation in the form of money from donators. Aids in the form of cash money open a possible occurence of misuse. The communication between the central East Java Province IRC with the shelters at the disaster sites so far was still conducted using phone calls or using SMS and whatsapp chats. The use of this kind of media caused information inaccuracy and outdated information on the goods distributions from central to the shelters. It took a very long time to find out the quantity of the real supplies. There is also a possibility of data redundancy. As the information comes from many different people, not concentrated in one particular person, the information on the needs of goods at the disaster sites are often confusing. Consequently, the goods sent cannot match the actual needs at the disaster site. Based on the analysis of the old system and the problem faced, an integrated system is needed to manage the communication between IRC, the shelters, volunteers and donors. This study is focusing specifically on the development of mobile application for volunteers.

\subsection{Proposed system}

Based on the analysis, an integrated system is needed to handle the communication problem among the central IRC, donors and volunteers. The proposed entire system can be viewed in Figure 1. The center of the database management is situated at the Information System logistic server, where all data and information are kept. The donors can transfer their donations in the form of money via banks directed to the accounts of IRC. IRC accumulates all donations and allocates all relief to the disaster sites according to the appropriate needs for each site. The relief logistics will be sent to the disaster site, directly from the central IRC or via 
orders to the appointed online convenience stores or supermarkets using the integrated network of Information System logistic. A volunteer in charge of receiving the aids at the shelters of the disaster areas to ensure that the relief logistics match the ones sent by the central IRC. When the logistics are sentthe shelter officers will give confirmation to the server, using their smartphones. Thus the central IRC will be able to view and verify that the logistics reliefs have been received at the shelter. The volunteers at the disaster site will distribute the logistics taken from the shelter to the disaster victims. When the supplies at the shelter decline and need additional supplies, the shelter officers or volunteers can input the logistics needs using the shelter application. If approved, the central IRC will send the logistics requested directly to the shelters or order from the covenience stores.

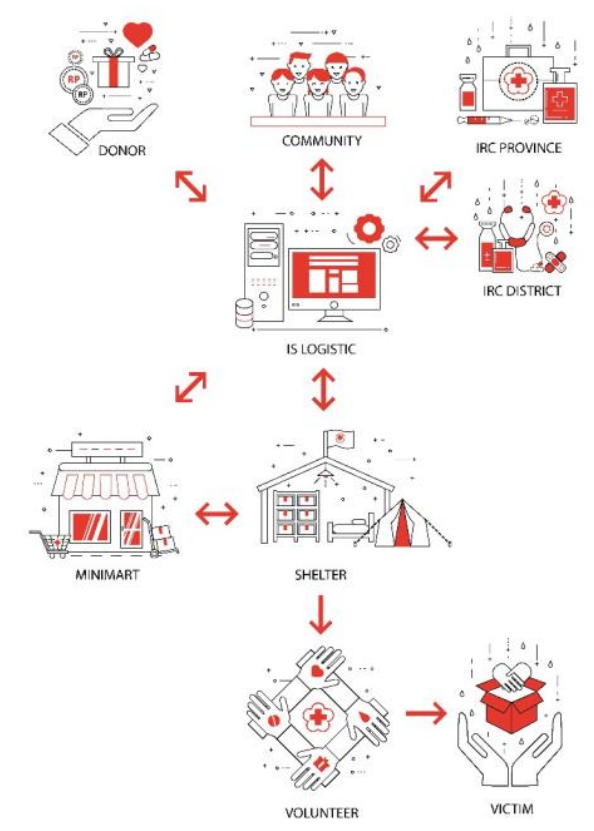

Figure 1: Humanitarian Integrated Logisticss Information Systems

\subsection{Design of process modelling}

The design of the Data Flow Diagram Level 0 can be viewed in Figure 2. The logistics information system consists of 6 processes: Managing Master data, Accepting Donations, Order and Receiving of Goods, Goods Distribution. Requesting the Needs, and Reporting. Figure 3 shows the design of DFD level 1 from the process of Receiving and Distribution of goods. In Figure 3, there is also detailed process for Volunteers Receiving Goods at the Shelters and Volunteers Distributing Goods as parts of the Distribution Goods process. In this process, the volunteers distribute the goods to the victims and record the goods distributed.

\section{Experimental Result and Discussion}

The testing for the application was conducted using mobile phones. The system for volunteers and shelters was tested against its features. Firstly, to check whether the goods needed were available or not, the volunteers viewed the supplies availability at the shelters. If the goods needed were not available, then the volunteers requested to the central IRC, using the menu Add Goods Request as seen in Figure 4. The administrator of the central IRC accepted the list of the goods requested. The administration officer checks the availability of the supplies meant to be sent to the shelters that had sent the request of goods. The status of the list of goods would be "Requested", waiting for approval from the administration officer of central IRC, as seen in Figure 5. 


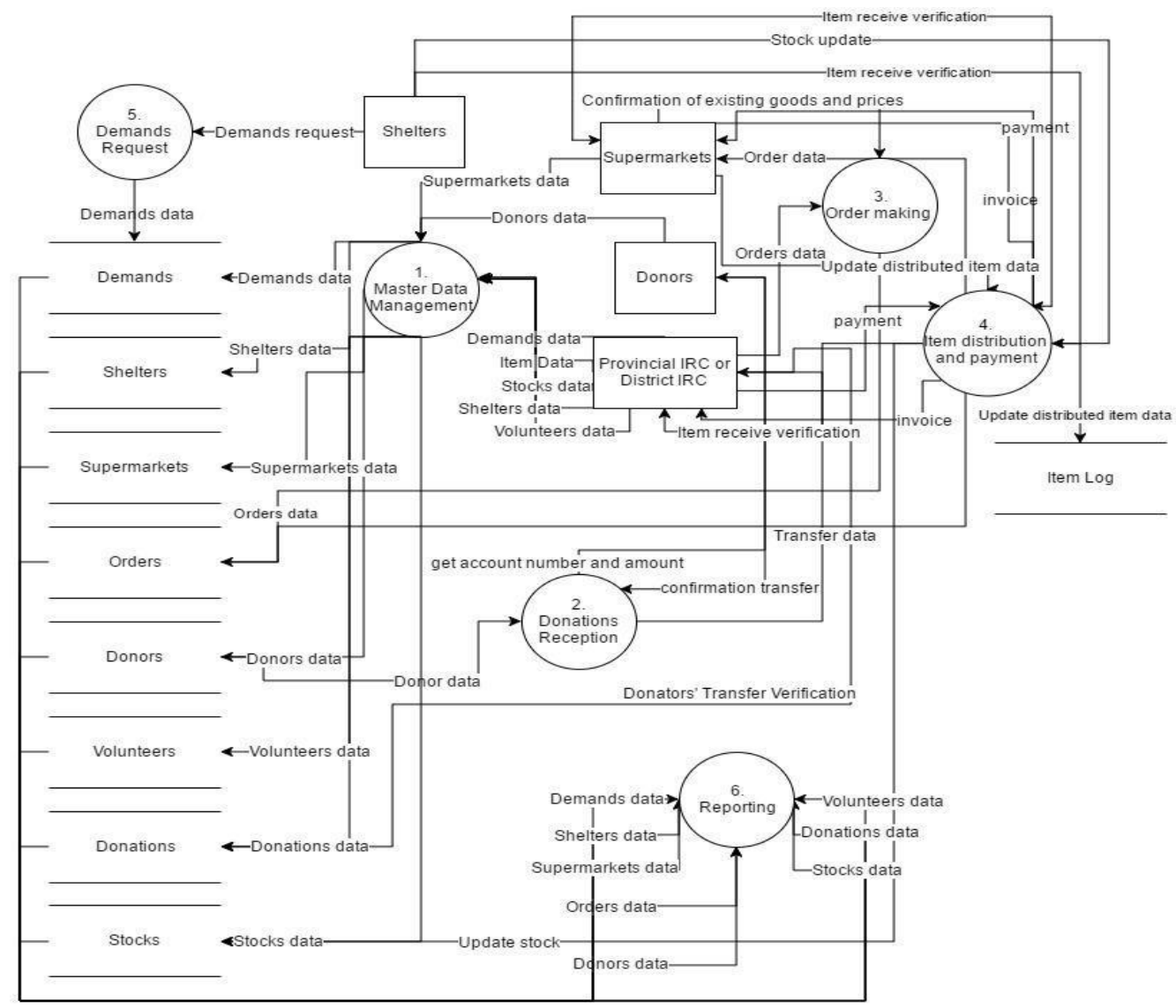

Figure 2: Data Flow Diagram Level 0

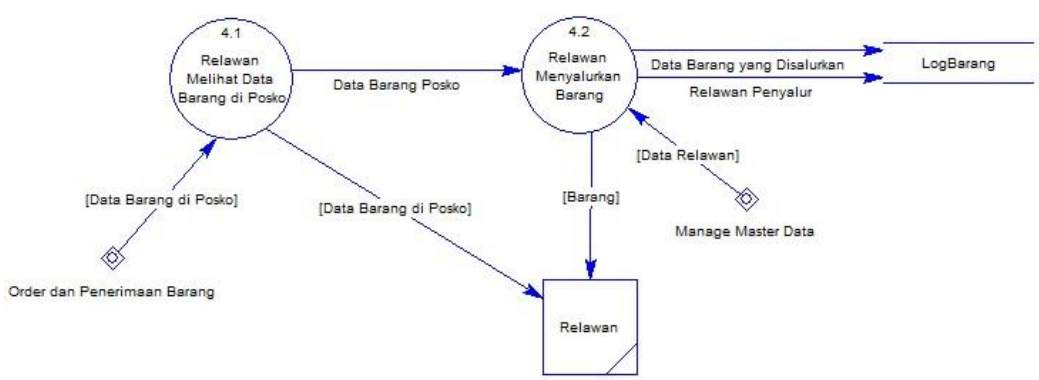

Figure 3: Data Flow Diagram Level 1

The list of goods to be sent would be saved in the Table "List of Transferring Goods" with the status "Sent". It means that the request had been sent to the shelter that had requested the goods (Figure 6). The volunteers at the shelter could check the additional goods received by viewing "Supply Card" at the dashboard for the administration officer of the shelter as seen in Figure 7. After the goods arrived at Gresik Shelter, the volunteers on duty in Gresik could input the information of the goods, which meant to be distributed, to the disaster victims, into the application for IRC volunteers, as seen in Figure 8.
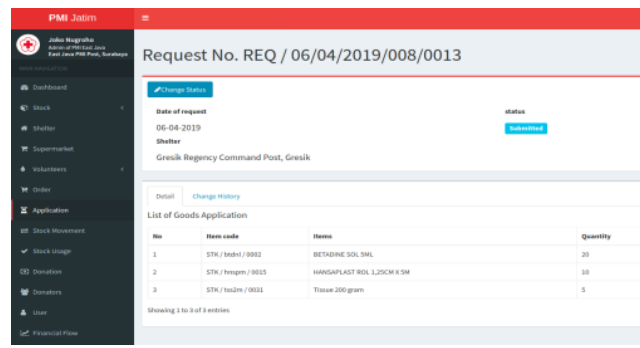

Figure 4: Adding Goods Request

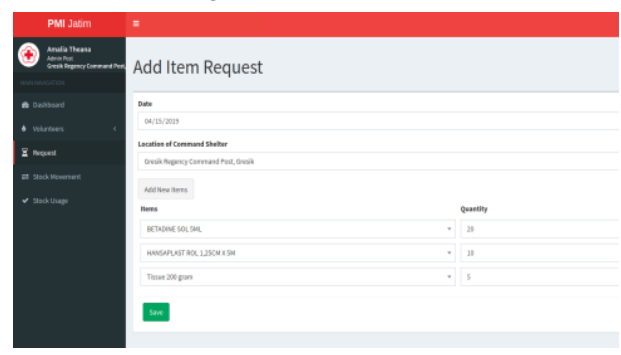

Figure 5: List of Goods needed 


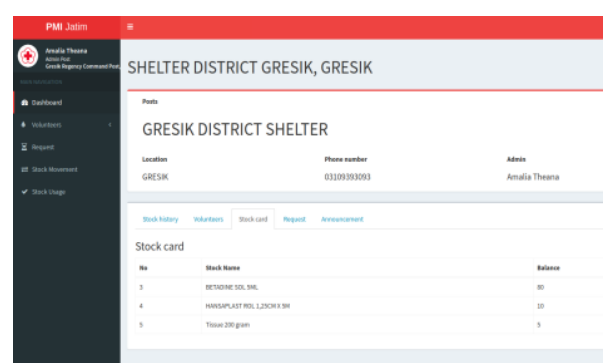

Figure 6: List of Goods sent to the Shelter

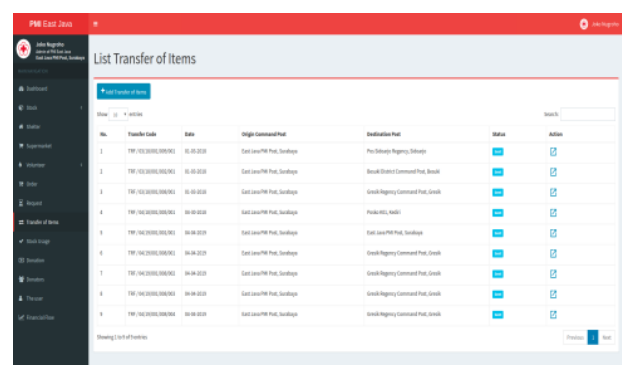

Figure 7: Goods Received at the Shelters

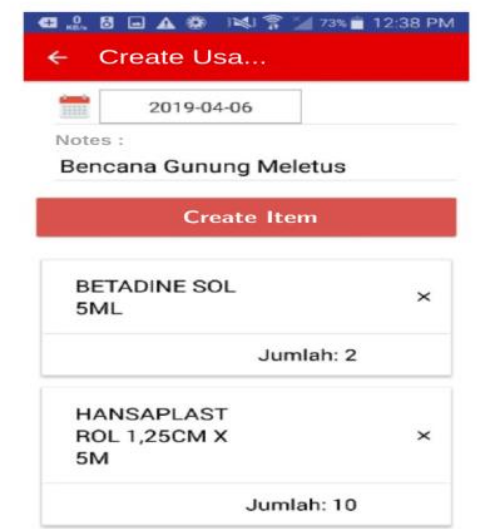

Figure 8: The Goods channeled to the Victims

Table 1: The Difference between the Old and New System

\begin{tabular}{|l|l|l|}
\hline & \multicolumn{1}{|c|}{ Old System } & \multicolumn{1}{c|}{ New System } \\
\hline Technology & Not integrated & Integrated \\
\hline Information Flow & Several stages & One stage \\
\hline Relief Distribution & Based on what is available & Correspond to what is required \\
\hline Provision Data Accuracy & Low accuracy & High Accuracy \\
\hline
\end{tabular}

This information system design includes some differences between the old and new system as viewed in Table 1. There have been some developments at the new system compared to the old system. At the old system, the information technology used was not entirely integrated. There were some types of technologies used at the old system. Whereas the new proposed system integrates the information system for volunteers, shelters for keeping the logistics up to the donators in one system, though not all activities have been using information technology. As the old system was not an integrated system, the flow of information was conducted in stages from the volunteers to the central IRC, to the warehouses and to the donors. This flow needs quite sometime that allows biased information to happen. Meanwhile the new system allows the flow of information to be carried out at one stage and centralized. It reduces the rate of biased information to be channelled. The system of disaster channel becomes a very different system compared to the old system. Although the information on the disaster needs had been requested from the disaster site, the goods to be sent to the shelters, tended to focus on the goods available at the warehouse of the central IRC. The types and quantity of the goods sent were often different from those goods in real needs. At the new proposed system, the goods to be channelled are those really needed at the disaster site and effectively used by the disaster victims. The donors will also be able to find out the goods needed at the disaster site and donate effectively. The other impact of the integrated technology is to increase the level of data accuracy of the supplies, which was quite low at the old system. There will also be proofs that the goods sent are really channelled to the disaster victims who really need them. So in short, the new system will present better-integrated data compared to the old one. The information flow will be more integrated. The goods sent and donated, correspond more to the needs of the disaster victims with high level of accuracy. However, this new system 
is still at the preliminary study. Further development related to the application and obstacles that might come up at the disaster sites. Adjustments should be carried out based on the problems found at the sites.

\section{Conclusions}

Based on the mobile application testing, it was concluded that the mobile application developed was of great help for the volunteers to channel the goods to the victims, corresponding to their needs. The application was able to give accurate information on the process of requested goods from the volunteers, on the quantity of supplies at the shelters and on the accurate remaining amount of stocks available at the central IRC, though there were still obstacles found at the disaster sites.

\section{Acknowledgements}

This research was conducted and accomplished by the grants from the Directorate General of Higher Education Indonesia (DIKTI) using the scheme of "Penelitian Terapan 2019". We would like to thank also to The Centre of Research of Petra Christian University for assisting us in managing the grants.

\section{References}

[1] Palang Merah Indonesia (PMI). http://www.pmi.or.id/index.php/aktivitas/pelayanan/manajemen-bencana/tanggapdarurat-bencana.html.(2012)

[2] Setiabudi, D.H., et.al. New Disaster Aid Information System Model for Indonesia Red Cross: A Case Study in East Java Province, International Journal of Supply Chain Management, Vol \& No 3, 2018, pp.9-15

[3] Zaroni. Manajemen Logistik Penanggulangan Bencana, 2016. http://supplychainindonesia.com/new/manajemenlogistik-penanggulangan-bencana-bagian-1/

[4] Astarita V. et.al. Mobile for emergencies M4EM: a cooperative software tool for emergency management operations, Procedia Computer Science 134 (2018) 433-438

[5] Van Wassenhove, L.N. Humanitarian Aid Logistics: Supply Chain Management in High Gear. Journal of Operational Research Society, 2006. 57, 475-489.

[6] Owusu-Kwateng, Kwame et.al. Disaster relief logistics operation: an insight from Ghana, International Journal of Emergency Services, 2017. Vol. 6 Issue: 1, pp.4-13

[7] Thomas, A. \& Kopczak, L. From Logistics to Supply Chain Management: The path forward in the humanitarian sector, white paper, Fritz Institute, San Francisco, CA. 2005.

[8] Serrato-Garcia,M.A. et.al. Multi objective optimization for Humanitarian Logistics Operations Through the Use of Mobile Technologies. Journal of Humanitarian Logistics \& Supply Chain Management, 2016. Volume: 6 Issue: 3

[9] Abushaikhaa, I. and Schumann-Bölscheb, D. Mobile Phones: Established Technologies For Innovative Humanitarian Logistics Concepts. Procedia Engineering 159 ( 2016 ) 191 - 198 